DONGMEI YAN, Ph.D. ${ }^{1}$

E-mail: ydm_1988@163.com

JIANHUA GUO, Ph.D. ${ }^{1}$

(Corresponding Author)

E-mail:jg2nh@yahoo.com

ZHAO LIU, Ph.D. ${ }^{1}$

E-mail: 195681809@qq.com

WEI HUANG, Ph.D. ${ }^{1}$

E-mail: seuhwei@126.com

${ }^{1}$ Intelligent Transportation System Research Center

Southeast University, Road of Southeast University 2,

Nanjing, 211189, P. R. China
Intermodal Transport

Preliminary Communication

Submitted: 12 May 2019

Accepted: 14 Oct. 2019

\title{
A NOVEL HYBRID EVALUATION METHOD FOR TRANSFER EFFICIENCY ASSESSMENT BETWEEN RAIL TRANSIT AND PUBLIC BICYCLES
}

\begin{abstract}
This paper proposes a new hybrid evaluation method including Improved Analytic Hierarchy Process (IAHP), Entropy Method (EM), and Grey Comprehensive Evaluation Method (GCEM) to assess the transfer efficiency between rail transit and public bicycles. In particular, the IAHP method that replaces the nine-scale approach with three-scale approach to naturally meet the consistency requirements is applied to qualitatively calculate the weights of evaluation indices, the EM method is utilized to calculate the weights of evaluation indices with relatively high degrees of quantification, and the GCEM method is used to calculate the transfer efficiency between rail transit and public bicycles. In addition, a three-level evaluation-index system including target level, criteria level and index level is established. A numerical example is also provided to verify the feasibility of the proposed hybrid evaluation method and explore the reasons for low transfer efficiency between rail transit and public bicycles.
\end{abstract}

\section{KEY WORDS}

rail transit; public bicycles; transfer efficiency; analytic hierarchy process; entropy method; grey comprehensive evaluation method;

\section{INTRODUCTION}

Public bicycle-sharing system has become increasingly popular in recent years [1]. The combined use of rail transit and public bicycles for one trip has increased dramatically in many countries [2]. The increasing interest stems from the fact that public bicycles can help solve the problem of "the last mile" of rail transit. As a supplement mode, public bicycles are faster than walking and more flexible than other public transportation modes [3, 4]. However, transfer efficiency between rail transit and public bicycles is definitely low. This may be because the long transfer distance, the imperfect transfer signs, and the insufficient transfer facilities restrict the development of public transportation and reduce the attractiveness of public transportation [5]. Thus, it is necessary to assess transfer efficiency between rail transit and public bicycles to further identify the reasons for low transfer efficiency.

Although the rapid growth in the joint use of rail transit and public bicycles has been recognized, research on the transfer efficiency evaluation between rail transit and public bicycles is extremely insufficient [6]. Thus, the objective of this paper is to develop a hybrid evaluation method that includes Improved Analytic Hierarchy Process (IAHP), Entropy Method (EM), and Grey Comprehensive Evaluation Method (GCEM) to assess the transfer efficiency between rail transit and public bicycles. More specifically, the weights of indices are given by the IAHP and EM methods, and the GCEM method is used to calculate the transfer efficiency between rail transit and public bicycles. A numerical example is provided to illustrate the feasibility of the proposed hybrid evaluation method.

The organization of this paper is as follows. Section 2 provides a brief overview of transfer efficiency evaluation method. Section 3 establishes an evaluation-index system for the transfer efficiency assessment between rail transit and public bicycles. Section 4 develops a hybrid evaluation method to 
assess transfer efficiency between rail transit and public bicycles. Section 5 provides a numerical example based on real-world data from six transfer stations selected in Nanjing to verify the feasibility of the proposed hybrid evaluation method. Section 6 gives the conclusions of the paper.

\section{LITERATURE REVIEW}

There have been extensive investigations on transfer efficiency evaluation. Chen and Chen [7] employed the Analytic Hierarchy Process (AHP) to evaluate the transfer efficiency between intercity rail and conventional public transit. Song et al. proposed an AHP method to evaluate transfer efficiency between rail transportation modes [8]. Sun et al. proposed a two-stage data envelopment analysis (DEA) method to evaluate transfer efficiency of the urban public transportation terminal [9]. Sun et al. constructed a structural equation model to evaluate transfer efficiency of rail transit P\&R facilities [10]. Cheng et al. presented a multi criteria/attribute decision-making (MCDM/MADM) model for measuring transfer efficiency between urban rail station and its feeding bus stops [11]. Xu et al. established a generalized cost function model to quantitatively analyse transfer efficiency inside the transfer station [12]. However, although there has been a large number of studies on transfer efficiency evaluation, little research has been done on the transfer efficiency evaluation between rail transit and public bicycles. For example, Guo and Wang applied the AHP approach to evaluate the transfer efficiency between rail transit and public bicycles [13].

It should be noted that the above-mentioned studies on the transfer efficiency assessment focus on the single evaluation method. It is well known that the single evaluation method has its own defects. To overcome deficiencies of the single evaluation method, more and more attention has been paid to hybrid evaluation methods. Xu et al. employed grey correlation method and the principal component analysis method to evaluate transfer efficiency between urban metro and buses [14]. Zhu et al. combined grey relation projection analysis method with information entropy theory to evaluate transfer efficiency of rail transportation hub [15]. Xia and Ma applied grey entropy method to determine the optimal transfer stations scheme for rail transit and conventional bus [16]. Hence, a question arises: is it feasible to construct a hybrid evaluation method for transfer efficiency assessment between rail transit and public bicycles? To the best of our knowledge, the results on this problem are rare, which remains an interesting research topic.

Obviously, the transfer efficiency between rail transit and public bicycles has not been fully investigated. This research gap is the first motivation for this paper. In addition, it has been common practice in previous research to evaluate transfer efficiency between rail transit and public bicycles without explicit consideration of the combined use of subjective weight and objective weight. Tackling this issue is the second motivation for this paper. Thus, this paper proposes a novel hybrid evaluation method to assess the transfer efficiency between rail transit and public bicycles by combining IAHP, EM and GCEM.

\section{ESTABLISHMENT OF EVALUATION INDEX SYSTEM}

The evaluation-index system is the basis of transfer efficiency assessment between rail transit and public bicycles. It is crucial to select representative evaluation indices so that each index is relatively independent and easy to quantify. A three-level evaluation-index system including objective lev$\mathrm{el}$, criteria level and index level is established, as shown in Figure 1.

Average transfer time is the average time required for the passengers to complete the entire transfer process, including walking time, time of ticket purchase, and waiting time. Here, the transfer process refers to the process of passengers getting off the public bicycle to taking the rail transit. This index measures the fastness and compactness of the transfer process.

$T=\frac{\frac{1}{n} \sum_{i=1}^{n} L_{i}}{\bar{V}}+\frac{\sum_{i=1}^{n} T_{i}^{\prime} P_{i}^{\prime}}{\sum_{i=1}^{n} P_{i}^{\prime}}+\frac{\sum_{i=1}^{n} T_{i}^{\prime \prime} P_{i}^{\prime \prime}}{\sum_{i=1}^{n} P_{i}^{\prime \prime}}$

where $T$ is the average transfer time [min]; $n$ is the total number of transfer passengers; $L_{i}$ is the walking distance of transfer passenger $i$ from the public bicycle station to the rail transit station $[\mathrm{m}] ; \bar{V}$ is the average walking speed of all transfer passengers, which is $66[\mathrm{~m} / \mathrm{min}] ; T_{i}^{\prime}$ is the time of ticket purchase of transfer passenger $i$ [min]; $P_{i}^{\prime}$ is 1 if transfer passenger $i$ is purchasing the ticket, 0 otherwise; $T_{i}^{\prime \prime}$ is the time when transfer passenger $i$ waits for rail transit [min]; $P_{i}^{\prime \prime}$ is 1 if transfer passenger $i$ is waiting to take the rail transit, 0 otherwise. 


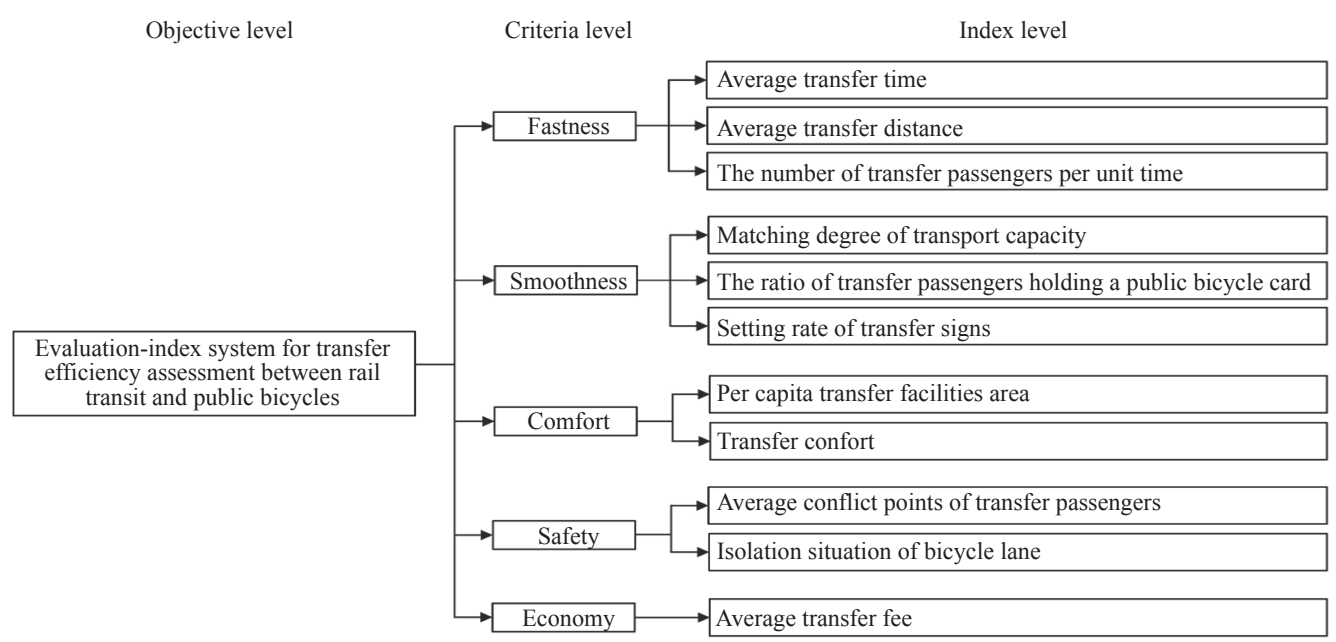

Figure 1 - Evaluation-index system of transfer efficiency

Average transfer distance is defined as the ratio of the transfer distance of all transfer passengers to the total number of transfer passengers, which measures the rationality of the layout of public bicycle stations.

$$
\bar{L}=\frac{\sum_{i=1}^{n} L_{i}}{n}
$$

where $\bar{L}$ is the average transfer distance $[\mathrm{m}] ; L_{i}$ is transfer distance of transfer passenger $i[\mathrm{~m}] ; n$ is the total number of transfer passengers.

The number of transfer passengers per unit time is considered to be the ratio of the total number of transfer passengers to the statistical time. The greater the number of transfer passengers per unit time, the higher the transfer efficiency will be.

$Q=\frac{Q^{\prime}}{\widetilde{T}}$

where $Q$ is the number of transfer passengers per unit time [person/min]; $Q^{\prime}$ is the total number of transfer passengers in the statistical time; $\widetilde{T}$ is the length of statistical times [min].

Matching degree of transport capacity is the ratio of the number of people who need to transfer from other transport modes to rail transit to the transport capacity of transfer stations during peak hours. This index measures the adaptability of the transfer infrastructure configuration.

$$
y=\frac{\sum_{i=1}^{k} Q_{i}}{E}
$$

where $y$ is the matching degree of transport capacity; $Q_{i}$ is the number of transfer passengers for transport mode $i$ during peak hours; $E$ is the transport capacity of rail transit stations during peak hours [person]; $k$ is the total number of transport modes.
The ratio of transfer passengers holding a public bicycle card is interpreted as the percentage of the transfer passengers holding a public bicycle card to the total transfer passengers. This index measures the convenience of the transfer passengers.

$K=\frac{Q^{\prime \prime}}{n}$

where $K$ is the ratio of passengers holding a public bicycle card; $Q^{\prime \prime}$ is the number of transfer passengers holding a public bicycle card; $n$ is the total number of transfer passengers.

Setting rate of transfer signs is the percentage of the number of transfer signs set to the number of transfer signs that should be set in public bicycle stations and rail transit stations. It measures the smoothness of the transfer process

$\delta=\frac{M}{M^{\prime}}$

where $\delta$ is the setting rate of transfer signs; $M$ is the number of transfer signs set in public bicycle stations and rail transit stations [PCS]; $M^{\prime}$ is the number of transfer signs that should be set in public bicycle stations and rail transit stations [PCS].

Per capita transfer facilities area refers to the ratio of the area of the rail transit stations to the number of passengers who transfer from public bicycles to rail transit. It measures the comfort of passengers during the transfer process. It also effectively evaluates the adaptability of transfer facilities.

$S=\frac{S^{\prime}}{Q^{\prime \prime}}$

where $S$ is per capita transfer facilities area $\left[\mathrm{m}^{2}\right]$; $S^{\prime}$ is the area of the rail transit stations $\left[\mathrm{m}^{2}\right] ; Q^{\prime \prime}$ is the number of passengers who transfer from public bicycles to rail transit. 
Transfer comfort is interpreted as the satisfaction level obtained by the transfer passengers from the service of the transfer stations. It measures the service level of the transfer stations. In particular, $\mu_{1}=\frac{1}{2}, \mu_{2}=\frac{1}{3}$, and $\mu_{3}=\frac{1}{6}$ are determined by historical data and expert experience [17].

$\varepsilon=\mu_{1} h_{1}+\mu_{2} h_{2}+\mu_{3} h_{3}$

where $\mu_{1}, \mu_{2}$, and $\mu_{3}$ are the coefficients of transfer service level; $h_{1}, h_{2}$, and $h_{3}$ represent the situation of transfer signs, cover facilities, transfer channel and platform equipment in the transfer process.

Average conflict points of transfer passengers are interpreted as the intertwined influence degree of various transfer passengers flow in rail transit stations. It can evaluate the rationality of ingress/ egress settings for rail transit stations and traffic streamline settings. The fewer the conflict points at the transfer station, the higher the security of the transfer passengers will be. The values of the evaluation indices can be obtained by field investigation.

Isolation situation of bicycle lane consists of the physical isolation, sharing the same lane with the motor vehicles, sharing the same lane with pedestrians. This index is mainly used to measure the safety of transfer passengers. The values of the evaluation indices can be given by experience.
Average transfer fee can be explained as the ratio of the transfer fees of all passengers to the total number of transfer passengers. The transfer fee includes rail transit travel expenses and public bicycle rental fee. This index is one of the most important factors that affects traffic mode choice of the passengers during their trips.

$$
F=\frac{\sum_{i=1}^{n} F_{i}}{n}
$$

where $F$ is the average transfer fee (units: yuan); $F_{i}$ is the transfer fee of transfer passenger $i$ (units: yuan); $n$ is the total number of transfer passengers.

\section{METHODOLOGY}

A hybrid evaluation method is proposed to assess the transfer efficiency between rail transit and public bicycles. It uses IAHP and EM methods to determine the weights of the evaluation indices, and then uses the GCEM method to calculate the transfer efficiency between rail transit and public bicycles at each transfer station. The process of applying the proposed hybrid evaluation method to calculate the transfer efficiency between rail transit and public bicycles at each transfer station is shown in Figure 2 .

Table 1 - Values of $h_{1}, h_{2}$, and $h_{3}[18]$

\begin{tabular}{||l||c|c|c|c|c||}
\hline \hline Percentage [\%] & $0-30$ & $30-50$ & $50-70$ & $70-90$ & $90-100$ \\
\hline Situation of transfer signs $h_{1}$ & $0-2$ & $2-4$ & $4-6$ & $6-8$ & $8-10$ \\
\hline Situation of cover facilities $h_{2}$ & $0-3$ & $3-5$ & $5-7$ & $7-9$ & $9-10$ \\
\hline Situation of transfer channel and platform equipment $h_{3}$ & $0-4$ & $4-6$ & $6-7$ & $7-9$ & $9-10$ \\
\hline
\end{tabular}

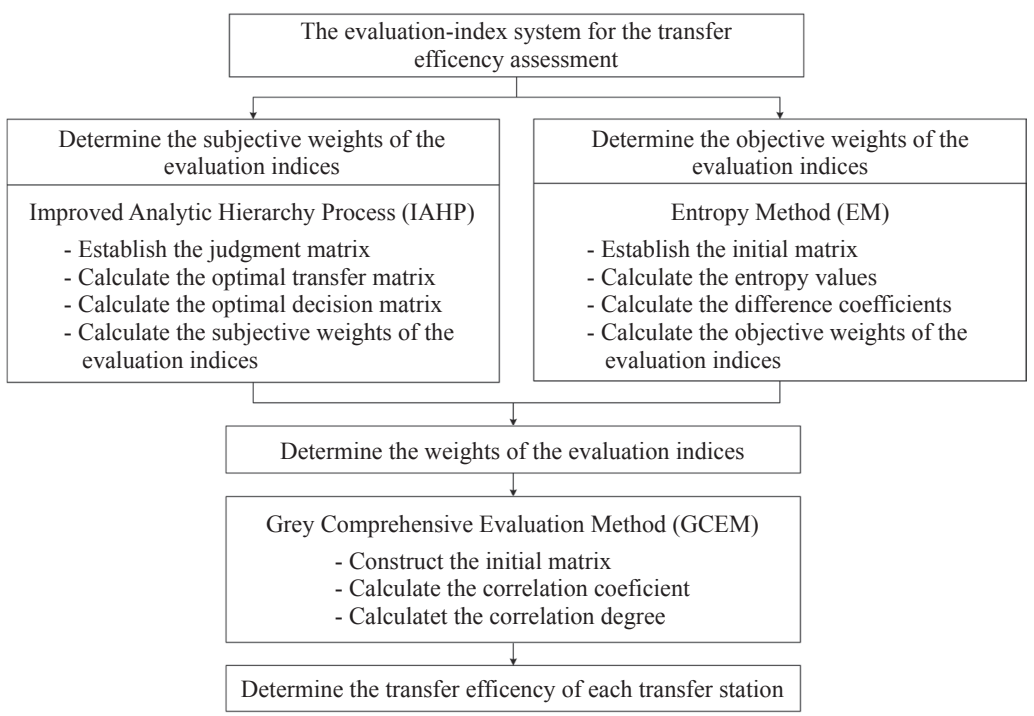

Figure 2 - Calculation process of transfer efficiency 


\subsection{Determination of the weights of the evaluation index}

The weights characterize the contribution of the evaluation indices to the goal. The weights of evaluation indices are given by IAHP and EM methods. More specifically, the IAHP method improved by three-scale method is used to qualitatively determine the weights of evaluation indices, and EM method is utilized to quantitatively determine the weights of evaluation indices.

\section{Calculation of the subjective weights of the evaluation indices}

The Analytic Hierarchy Process (AHP) [19-24] is a multi-criteria decision method developed by Saaty in the 1970s [25]. The IAHP method improves the AHP method by replacing the nine-scale method with a three-scale method. In this case, after a series of transformations are performed on the judgment matrix, the judgment matrix is a consistency matrix, so it naturally meets the consistency requirements [26]. In this paper, the AHP with three scales (-1, 1) is used to calculate the subjective weights of the evaluation indices, and its steps of calculating weights are as follows:

Step 1: The judgment matrix $C=\left(C_{i j}\right)_{m \times m}$ will be established by comparing the relative importance between indices. In other words, for each element in the adjacent higher layer, the relative importance between the indices in this layer is compared based on the experience and knowledge of experts [27]. The judgment matrix is described as follows.

$$
\begin{aligned}
C & =\left[\begin{array}{cccc}
C_{11} & C_{12} & \ldots & C_{1 m} \\
C_{21} & C_{22} & \ldots & C_{2 m} \\
\vdots & \vdots & \ddots & \vdots \\
C_{m 1} & C_{m 2} & \ldots & C_{m m}
\end{array}\right] \\
C_{i j} & =\left\{\begin{array}{l}
1, i \text { is more important than } j \\
0, i \text { is as important as } j \\
1, i \text { is not more important than } j
\end{array}\right.
\end{aligned}
$$

Step 2: To obtain the decision matrix, the optimal transfer matrix $T_{i j}$ is first calculated by Equation 11 .

$$
T_{i j}=\frac{1}{m} \sum_{k=1}^{m}\left(C_{i k}+C_{k j}\right)
$$

Substituting $T_{i j}$ into Equation 12, decision matrix $D_{i j}$ is further obtained.

$$
D_{i j}=\exp \left(T_{i j}\right)
$$

Step 3: The eigenvector corresponding to the largest eigenvalue is considered to be the weight of each element of the level. The product root method is used to calculate the eigenvector, which can be described as:

$$
\tau_{i}=\frac{\left(\prod_{j=1}^{m} D_{i j}\right)^{\frac{1}{m}}}{\sum_{j=1}^{m}\left(\prod_{j=1}^{m} D_{i j}\right)^{\frac{1}{m}}}
$$

\section{Calculation of the objective weights of evaluation} indices

The concept of entropy is derived from the principle of thermodynamics handling energy, and later introduced information theory by Shannon [28]. The EM method uses the value of information entropy to calculate the weights of evaluation indices [29]. It is worth noting that the difference coefficient is the key in the process of calculating the weights, because the difference coefficient and the weight of the index are proportional. The steps of using EM method to calculate the objective weights of evaluation indices are as follows:

Step 1: According to the original index values surveyed at the transfer stations, the initial matrix $A$ of evaluation indices is established. Matrix $A$ needs to be normalized to derive matrix $B$ because evaluation indices have different unit and property. If it is a benefit index (i.e., the bigger the better), the standardized value of evaluation index should be calculated by Equation 14 .

$Y_{h i}=\frac{X_{h i}}{\sum_{h=1}^{q} X_{h i}}$

where $X_{h i}$ is the value of evaluation index $i$ $(i=1,2, \ldots, m)$ of the transfer station $h(h=1,2, \ldots q)$. If it is a cost index (i.e. the smaller the better), the standardized value of evaluation index is calculated by Equation 14 based on reciprocal of the evaluation index value.

Step 2: According to the definition of entropy in the information theory, the entropy value of evaluation index $i$ is calculated by Equation 15 .

$$
\delta_{i}=-\gamma \sum_{h=1}^{q} Y_{h i} \ln Y_{h i}, \gamma=\frac{1}{\ln q}
$$

For evaluation index $i$, it gradually increases the influence of transfer efficiency assessment with the growth of the values of difference coefficients. In addition, the smaller the entropy value, the larger 
the weight coefficient of the index will be, and vice versa. The difference coefficient is calculated by Equation 16.

$\mu_{i}=1-\delta_{i}$

Step 3: Substituting the difference coefficients $\mu_{i}$ into Equation 17, the weights of evaluation indices are calculated by Equation 17.

$\alpha_{i}=\frac{\mu_{i}}{\sum_{i=1}^{n} \mu_{i}}$

Calculation of the weights of evaluation indices

The AHP with three scales $(-1,1)$ is first used to obtain the subjective weights of the evaluation indices, and then the objective weights of the evaluation indices determined by the EM are applied to revise the result calculated by the AHP with three scales (-1, 1). Finally, according to [29], Equation 18 is applied to calculate the weights of the evaluation indices as follows.

$$
w_{i}=\frac{\tau_{i} \alpha_{i}}{\sum_{i=1}^{n} \tau_{i} \alpha_{i}}
$$

\subsection{Calculation process of transfer efficiency}

Grey correlation degree is the key to the grey comprehensive evaluation method, which measures the correlation degree between evaluation indices. If the correlation degree calculated by GCEM method is large, it means that the evaluation indices of the transfer station are close to the optimal index; meanwhile, it indicates that the transfer efficiency of the transfer station is superior to other transfer stations. The ranking of transfer efficiency between rail transit and public bicycles at each transfer station is further obtained. The calculation process of the transfer efficiency between rail transit and public bicycles using the GCEM method can be divided into the following four steps:

Step 1: Let $J^{*}=\left[j_{1}^{*} j_{2}^{*}, \ldots j_{m}^{*}\right]$ be the set of optimal index values, where $j_{k}^{*}(k=1,2 \ldots, m)$ denotes element $k$ of set $J^{*}$. If an index with a large value is good, the maximum value of the evaluation index should be selected at each transfer station, and vice versa. Initial matrix $J$ is established as follows.

$J=\left[\begin{array}{cccc}j_{1}^{*} & j_{2}^{*} & \ldots & j_{m}^{*} \\ j_{1}^{1} & j_{2}^{1} & \ldots & j_{m}^{1} \\ \vdots & \vdots & \ddots & \vdots \\ j_{1}^{n} & j_{2}^{n} & \ldots & j_{m}^{n}\end{array}\right]$ where $j_{k}^{i}$ is the original value of evaluation index $k$ at transfer station $i(i=1,2, \ldots, n)$.

Step 2: It is assumed that there exists a range $\left[j_{k 1}, j_{k 2}\right]$, where $j_{k 1}$ and $j_{k 2}$ are the minimum and maximum values of evaluation index $k$ in all transfer stations, respectively. The original values of matrix $J$ are converted into dimensionless values by Equation 20.

$G_{k}^{i}=\frac{j_{k}^{i}-j_{k 1}}{j_{k 2}-j_{k 1}}$

Normalization matrix $G$ is further obtained as follows.

$G=\left[\begin{array}{cccc}g_{1}^{*} & g_{2}^{*} & \ldots & g_{m}^{*} \\ g_{1}^{1} & g_{2}^{1} & \ldots & g_{m}^{1} \\ \vdots & \vdots & \ddots & \vdots \\ g_{1}^{n} & g_{2}^{n} & \ldots & g_{m}^{n}\end{array}\right]$

Step 3: According to grey system theory, $g^{*}=\left[g_{1}^{*}, g_{2}^{*}, \ldots, g_{m}^{*}\right]$ represents a reference sequence, and $g=\left[g_{1}^{i}, g_{2}^{i}, \ldots, g_{m}^{i}\right]$ denotes a comparison sequence. The correlation coefficient between evaluation index $k$ and optimal index $k$ at transfer station $i$ is obtained by using the correlation analysis method. The correlation coefficients are calculated by Equation 22 as follows:

$\varepsilon_{i}(k)=\frac{\min _{i} \min _{k}\left|g_{k}^{*}-g_{k}^{i}\right|+\rho \max _{i} \max _{k}\left|g_{k}^{*}-g_{k}^{i}\right|}{\left|g_{k}^{*}-g_{k}^{i}\right|+\rho \max _{i} \max _{k}\left|g_{k}^{*}-g_{k}^{i}\right|}$

where $\rho$ is resolution factor, $\rho=0.5$.

Step 4: The $w_{i}$ calculated by AHP with three scales $(-1,1)$ and EM methods is substituted into $r_{i}=w_{i} \times \varepsilon_{i}(k)$ to calculate the correlation degrees. Specifically, if correlation degree $r_{i}$ is the largest, which means that $\left\{g^{i}\right\}$ is the closest to the optimal index $\left\{g^{*}\right\}$. In other words, it indicates that the transfer efficiency of transfer station $i$ is superior to other transfer stations. Thus, the ranking of the transfer efficiency between rail transit and public bicycles at each transfer station is obtained.

\section{NUMERICAL EXAMPLE}

\subsection{Data}

A field survey was conducted for six transfer stations (i.e. Jimingsi station, Fuqiao station, Daxinggong station, Minggugong station, Zhangfuyuan station and Sanshanjie station) in Nanjing. Twelve people were divided into six groups to inquire, photograph, and record at the designated transfer stations. The original values of the evaluation indices 
Yan D, Guo J, Liu Z, Huang W. A Novel Hybrid Evaluation Method for Transfer Efficiency Assessment between Rail Transit...

Table 2 - Initial values of evaluation indices

\begin{tabular}{||c|c|c|c|c|c|c|c|c|c|c|c||}
\hline Transfer stations & E1 & E2 & E3 & E4 & E5 & E6 & E7 & E8 & E9 & E10 & E11 \\
\hline \hline Jimingsi & 22 & 462 & 0.45 & 0.63 & 85 & 90 & 3.8 & 87 & 3 & 83 & 3 \\
\hline Fuqiao & 9.1 & 132 & 0.7 & 0.7 & 87 & 87 & 3.6 & 88 & 2 & 85 & 2 \\
\hline Daxinggong & 15 & 198 & 1.25 & 0.9 & 92 & 92 & 2.3 & 82 & 4 & 87 & 4 \\
\hline Minggugong & 10.6 & 139 & 0.95 & 0.8 & 90 & 88 & 2.6 & 85 & 3 & 88 & 3 \\
\hline Zhangfuyuan & 8.3 & 146 & 0.75 & 0.65 & 89 & 91 & 3.2 & 87 & 3 & 86 & 3 \\
\hline Sanshanjie & 6.5 & 106 & 0.5 & 0.6 & 90 & 86 & 3.5 & 90 & 2 & 86 & 2 \\
\hline
\end{tabular}

Note: E1 - average transfer time [min]; E2 - average transfer distance [m]; E3 - the number of transfer passengers per unit time [passengers/ min]; E4 - matching degree of transport capacity; E5 - the ratio of passengers holding a public bicycle card; E6 - setting rate of transfer signs; E7 - per capita transfer facilities area [m2/passenger]; E8 - transfer comfort; E9-average conflict points of transfer passengers; E10 isolation situation of bicycle lane; E11 - average transfer fee (yuan)

for all transfer stations obtained during the morning peak (7:30-9:30) and evening peak (4:30-6:30) are shown in Table 2.

\subsection{Calculation process}

Calculate the subjective weights of the evaluation indices

In order to construct a realistic judgment matrix, it is better to select more than 15 experts, including research scholars in the field of rail transit and public bicycles, as well as the government administrators. These experts are required to have more than five years of work experience. Then face-to-face questionnaires were conducted with them. For each element of criteria level, the elements of index level are compared to each other by three scales $(-1,1)$ based on the experience and knowledge of experts. More specifically, if the $i$-th element is more important than the $j$-th element, then judgment matrix $C_{i j}$ is equal to 1 , and vice versa, it is -1 . Moreover, if the two elements are equally important, judgment matrix $C_{i j}$ is equal to 0 . The comparison results given by most experts as the initial values of judgment matrix $C=\left(C_{i j}\right)_{m \times m}$ are selected as follows.

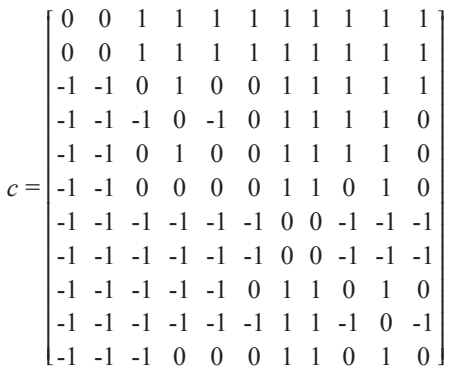

According to Equations 11 and 12, decision matrix $D_{i j}$ is easily obtained as follows:

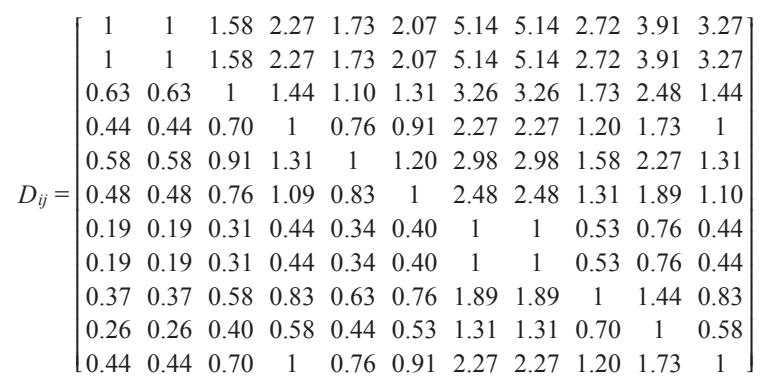

The subjective weights of evaluation indices are further calculated by Equation 13, i.e. $\tau_{1}=0.1828$, $\tau_{2}=0.1827, \quad \tau_{3}=0.1120, \quad \tau_{4}=0.0780, \quad \tau_{5}=0.1024$, $\tau_{6}=0.0852, \quad \tau_{7}=0.0343, \quad \tau_{8}=0.0343, \quad \tau_{9}=0.0650$, $\tau_{10}=0.0453, \tau_{11}=0.0780$.

Calculate the objective weights of the evaluation indices

Initial matrix $A$ is established from the survey data that have been accurately quantified.

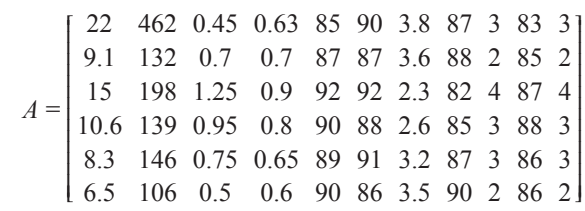

The data in matrix $A$ are then normalized by Equation 14 to obtain matrix $B$.

$\left[\begin{array}{lllllllllll}0.10 & 0.06 & 0.10 & 0.18 & 0.16 & 0.17 & 0.20 & 0.17 & 0.16 & 0.16 & 0.15\end{array}\right.$

$\begin{array}{llllllllllll}0.18 & 0.20 & 0.15 & 0.17 & 0.16 & 0.16 & 0.10 & 0.17 & 0.24 & 0.17 & 0.23\end{array}$

$B=\begin{array}{lllllllllll}0.16 & 0.13 & 0.27 & 0.13 & 0.17 & 0.17 & 0.12 & 0.16 & 0.08 & 0.17 & 0.12\end{array}$

$\begin{array}{lllllllllll}0.20 & 0.19 & 0.21 & 0.15 & 0.17 & 0.16 & 0.14 & 0.17 & 0.12 & 0.17 & 0.12\end{array}$

$\begin{array}{lllllllllll}0.17 & 0.18 & 0.16 & 0.18 & 0.17 & 0.17 & 0.17 & 0.17 & 0.16 & 0.17 & 0.15 \\ 0.20 & 0.25 & 0.11 & 0.19 & 0.17 & 0.16 & 0.18 & 0.17 & 0.24 & 0.17 & 0.23\end{array}$

$\left[\begin{array}{lllllllllll}0.20 & 0.25 & 0.11 & 0.19 & 0.17 & 0.16 & 0.18 & 0.17 & 0.24 & 0.17 & 0.23\end{array}\right]$

The entropy value of each evaluation index is calculated by Equation 15, i.e. $\delta_{1}=-0.962, \delta_{2}=$ $-0.958, \delta_{3}=-0.966, \delta_{4}=-0.995, \delta_{5}=-0.999, \delta_{6}=-0.999$, $\delta_{7}=-0.991, \quad \delta_{8}=-0.999, \quad \delta_{9}=-0.983, \quad \delta_{10}=-0.999$, $\delta_{11}=-0.983$. According to Equation 16, the difference coefficients are obtained, i.e. $\mu_{1}=0.038, \mu_{2}=0.042$, $\mu_{3}=0.034, \mu_{4}=0.05, \mu_{5}=0.001, \mu_{6}=0.001, \mu_{7}=0.009$, $\mu_{8}=0.001, \mu_{9}=0.017, \mu_{10}=0.001, \mu_{11}=0.017$. The objective weights of evaluation indices are further 
calculated based on Equation 17, i.e., $\alpha_{1}=0.2336$, $\alpha_{2}=0.2556, \quad \alpha_{3}=0.2109, \quad \alpha_{4}=0.0327, \quad \alpha_{5}=0.0011$, $\alpha_{6}=0.0010, \quad \alpha_{7}=0.0527, \quad \alpha_{8}=0.0014, \quad \alpha_{9}=0.1051$, $\alpha_{10}=0.0006, \alpha_{11}=0.1051$.

\section{Determine the weights of the evaluation indices}

The subjective weights of evaluation indices calculated by the AHP with three scales $(-1,1)$ and the objective weights of evaluation indices calculated by the EM method are substituted into Equation 18 to calculate the weights of evaluation indices, i.e. $w_{1}=0.3218, \quad w_{2}=0.3520, \quad w_{3}=0.1780, \quad w_{4}=0.0192$, $w_{5}=0.0008, w_{6}=0.0006, \quad w_{7}=0.0136, \quad w_{8}=0.0004$, $w_{9}=0.0515, w_{10} 0=0.0002, w_{11}=0.0618$.

Calculate the transfer efficiency between rail transit and public bicycles

In the first place, when the evaluation index with a small value is good, the minimum value of the evaluation index in each transfer station is selected, and vice versa. Matrix $J$ constructed from the original values of the evaluation indices is as follows.

$$
J=\left[\begin{array}{ccccccccccc}
6.5 & 106 & 1.25 & 0.6 & 92 & 92 & 3.8 & 90 & 2 & 88 & 2 \\
22 & 462 & 0.45 & 0.63 & 85 & 90 & 3.8 & 87 & 3 & 83 & 3 \\
9.1 & 132 & 0.7 & 0.7 & 87 & 87 & 3.6 & 88 & 2 & 85 & 2 \\
15 & 198 & 1.25 & 0.9 & 92 & 92 & 2.3 & 82 & 4 & 87 & 4 \\
10.6 & 139 & 0.95 & 0.8 & 90 & 88 & 2.6 & 85 & 3 & 88 & 3 \\
8.3 & 146 & 0.75 & 0.65 & 89 & 91 & 3.2 & 87 & 3 & 86 & 3 \\
6.5 & 106 & 0.5 & 0.6 & 90 & 86 & 3.5 & 90 & 2 & 86 & 2
\end{array}\right]
$$

In the second place, after normalizing matrix $J$ to matrix $G$ by Equation 20, it is easy to obtain the correlation coefficients based on Equation 22.

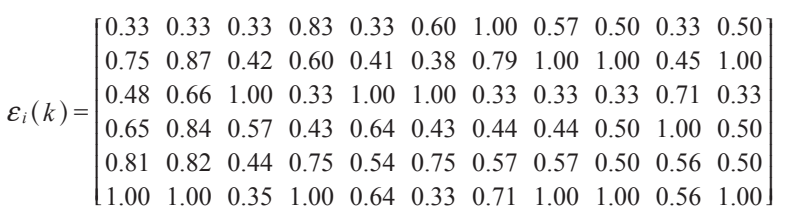

Finally, substituting the weight of evaluation index $i$, i.e. $w_{i}$, into $r_{i}=w_{i} \times \varepsilon_{i}(k)$ to calculate the correlation degrees, which are $r_{1}=0.371, r_{2}=0.760, r_{3}=0.614$, $r_{4}=0.680, r_{5}=0.707, r_{6}=0.879$. It is well known that the transfer efficiency gradually increases with the growth of the correlation degrees. Thus, the ranking of the transfer efficiency between rail transit and public bicycles at each transfer station is obtained.

\subsection{Result analysis}

\section{Weights analysis}

To validate the accuracy of the weight results, another improved analytic hierarchy process method is used to calculate the weights of evaluation indices. It is worth noting that it uses three scales
$(0,2)$ to construct the judgment matrix instead of three scales $(-1,1)$. Please refer to $[30,31]$ for detailed calculation steps of AHP with three scales ( 0 , 2 ). We further compare the weights calculated by AHP with three scales $(0,2)$, AHP with three scales $(-1,1)$, EM, combination method $(0,2)$ (i.e., AHP $(0,2)$ and $E M)$ and combination method $(-1,1)$ (i.e. AHP $(-1,1)$ and EM) as shown in Figure 3.

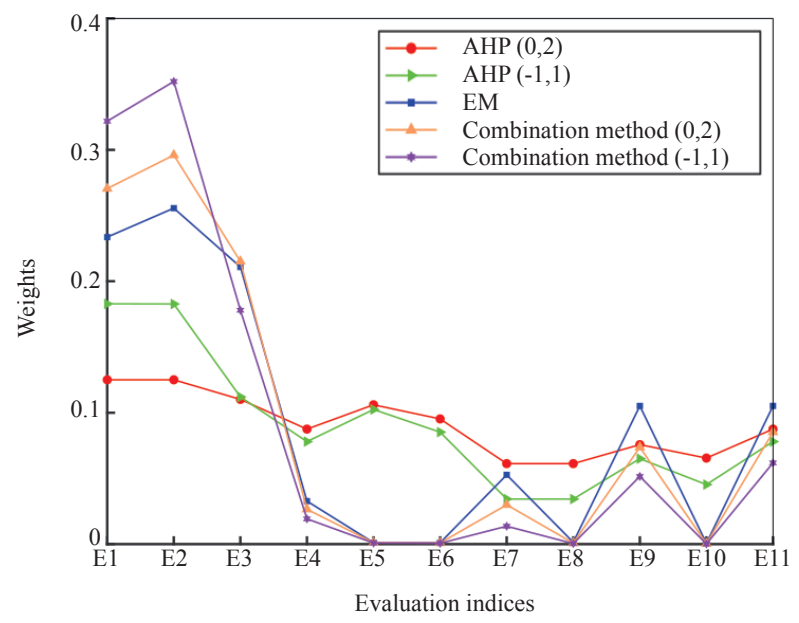

Figure 3 - Weight comparison between different methods

In Figure 3, it can be seen first that the sum of the weights of the average transfer time and the average transfer distance calculated by the combination method $(-1,1)$ is about $50 \%$, and the weight of the average transfer distance is the largest, i.e. $35.2 \%$, which means that the transfer distance should be taken into account during the layout planning of the public bicycle stations. Secondly, it can be seen that the weights of the isolation situation of bicycle lane are minimal, i.e. $0.6 \%$ which indicates that this index has the least influence on the transfer efficiency.

Thirdly, it can be seen that the weights calculated by the AHP $(-1,1)$ are significantly different from weights calculated by the EM method. Moreover, compared with the AHP $(-1,1)$ and EM, the results of the weights calculated by the combination method $(-1,1)$ indicate that the weights of the evaluation indices which have great influence on the transfer efficiency become larger, and the weights of the evaluation indices which have small influence on the transfer efficiency become smaller. It means that the combination method $(-1,1)$ can enhance the differences in the weights of evaluation indices. The above analysis also applies to the three scales $(0,2)$.

Finally, it can be seen that the ranking of the weights of the evaluation indices determined by the $\operatorname{AHP}(0,2)$ and the AHP $(-1,1)$ are the same. It can also be seen that the ranking of the weights of the 
evaluation indices calculated by the combination method $(0,2)$ and the combination method $(-1,1)$ are the same. It means that the selection of three scales will not affect the results of the weights. In this case, the accuracy of the results of the weights is enhanced.

\section{Transfer efficiency analysis}

In this section, we use the analytic hierarchy process with three scales $(0,2)$-based grey comprehensive evaluation method (AHP-GCEM $(0,2)$ ), AHP-GCEM $(-1,1)$, entropy method-based grey comprehensive evaluation method (EM-GCEM), hybrid method $(0,2)$ (i.e., AHP $(0,2), \mathrm{EM}$ and GCEM) and hybrid method $(-1,1)$ (i.e., AHP $(-1,1)$, EM and GCEM) to calculate the transfer efficiency of each transfer station, and the results are shown in Figure 4.

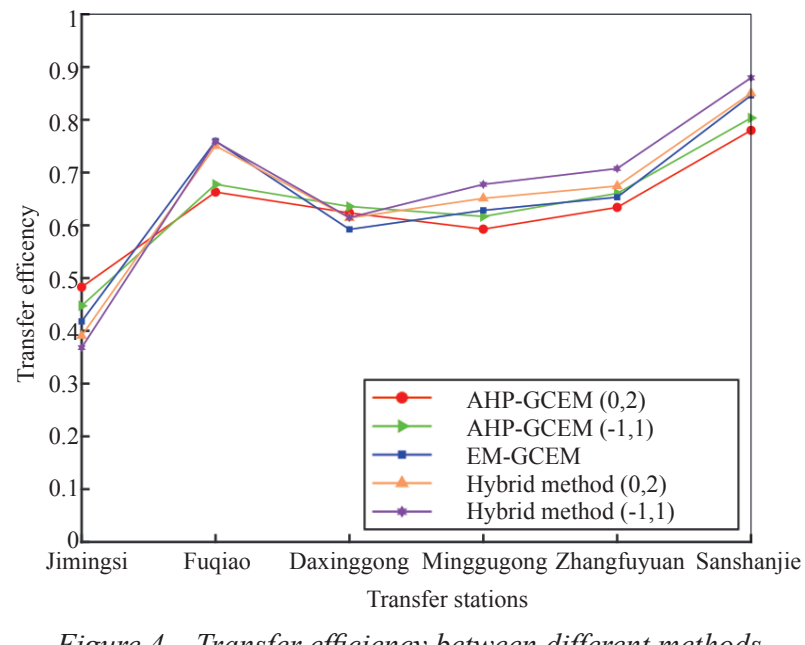

In Figure 4, it can be observed first that the transfer efficiency of Sanshanjie station is the highest, i.e. 0.879 , and the transfer efficiency of Jimingsi station is the lowest, i.e. 0.371 . The highest transfer efficiency of Sanshanjie station could be attributed to the least average transfer time and the shortest average transfer distance. In contrast, the longest transfer distance between the Jimingsi station and the nearest public bicycle station results in the lowest transfer efficiency.

Secondly, it can be observed that the hybrid method $(-1,1)$ can enhance the difference in transfer efficiency. For example, compared with the results of the AHP-GCEM $(-1,1)$ and EM-GCEM methods, the transfer efficiency of Sanshanjie station and Zhangfuyuan station becomes higher, and the transfer efficiency of Jimingsi station becomes lower. The above analysis is equally applicable to the three scales $(0,2)$.

Finally, it can be observed that the rankings of transfer efficiency of each transfer station calculated by AHP-GCEM $(0,2)$ and AHP-GCEM $(-1,1)$ are the same. Similarly, the rankings of transfer efficiency calculated by hybrid $(0,2)$ and hybrid $(-1,1)$ are also the same. It reconfirms that different threescale methods will not affect the results of transfer efficiency. Meanwhile, it also enhances the accuracy of the results of transfer efficiency.

\section{CONCLUSION}

This paper proposes a hybrid evaluation method for the transfer efficiency assessment between rail transit and public bicycles. First, a scientific evaluation-index system was established. Second, the weights of the evaluation indices were given by combining the IAHP method and EM method. More specifically, the IAHP method was used to determine the subjective weights of the evaluation indices, and the EM method was used to determine the objective weights of the evaluation indices. Finally, the GCEM method was applied to calculate the transfer efficiency between rail transit and public bicycles at each transfer station.

To validate the proposed method, we used the survey data of six transfer stations in Nanjing to calculate the weights and transfer efficiency. The results indicate that the sum of the weights of the average transfer time and the average transfer distance calculated by the combination method $(-1,1)$ is approximately $50 \%$, which means that these two evaluation indices play more important roles in the transfer efficiency assessment between rail transit and public bicycles. The weight of isolation situation of bicycle lane is minimal, i.e. $0.6 \%$ which indicates that this index has the least influence on transfer efficiency. In addition, according to the ranking of the transfer efficiency, it can be concluded that the transfer efficiency of Sanshanjie station calculated by the combination method $(-1,1)$ is 0.879 , which is the highest compared to other transfer stations. In contrast, the transfer efficiency of the Jimingsi station is the lowest, i.e. 0.371 .

To verify the accuracy of the results of the weights and transfer efficiency, we applied AHP $(0,2)$ and AHP $(-1,1)$ to calculate the weights of evaluation indices. The results indicate that the 
ranking of the weights of the evaluation indices determined by these two methods are the same, which enhances the accuracy of the results of the weights of the evaluation indices, thereby enhancing the accuracy of the results of transfer efficiency.

Some suggestions will be proposed to improve the transfer efficiency between rail transit station and public bicycles. For example, the layout between rail transit stations and public bicycle stations should be considered. The locations of the public bicycle stations should be clearly marked inside the rail transit stations so that the transfer passengers can reach the public bicycle stations quickly and accurately. In addition, smart cards between rail transit and public bicycles should be popularized to reduce the transfer time and attract more travellers to choose public transportation.

In the future, the principal component analysis and factor analysis can be used to further select the evaluation indices. In addition, other methods for evaluating the transfer efficiency between rail transit and public bicycle can be explored, such as Data Envelopment Analysis (DEA), fuzzy comprehensive evaluation method.

\section{ACKNOWLEDGEMENT}

This research is supported by the National Natural Science Foundation of China (No. 61573106), the Jiangsu Provincial Key Laboratory of Networked Collective Intelligence under Grant (No. BM2017002), and the Postgraduate Research \& Practice Innovation Program of Jiangsu Province (No. KYLX16_0271).

\section{间冬梅1}

E-mail: ydm_1988@163.com

郭建华 1 (通讯作者)

E-mail:jg2nh@yahoo.com

刘钊 ${ }^{1}$

E-mail: 195681809@qq.com

黄卫 ${ }^{1}$

E-mail: seuhwei@126.com

1 东南大学智能运输系统研究中心,

江苏 南京, 211189

一种新的轨道交通与公共自行车换乘效率评价 的混合评价方法

摘要

本文提出了一种新的由改进的层次分析法 $(I A H P)$ 、熵权法 (EM) 和灰色综合评价法 (GCEM) 组成的混合评价方法, 并应用该方法评估 轨道交通与公共自行车之间的换乘效率。特别地,
改进的层次分析法是通过三尺度法代替九尺度法, 自然满足一致性要求, 进而采用改进的层次分析法 定性地计算评价指标的权重, 并采用 $\mathrm{E} M$ 方法定量地 计算评价指标的权重, 在此基础上, 采用 GCEM方 法计算轨道交通与公共自行车之间的换乘效率。此 外, 我们也建立了目标层、准则层和指标层的三级 评价指标体系。最后, 通过实例验证所提出的混合 评价方法的可行性, 并探讨轨道交通与公共自行车 之间换乘效率低的原因。

\section{关键词}

轨道交通; 公共自行车; 换乘效率;

层次分析法; 熵权法; 灰色综合评价法

\section{REFERENCES}

[1] Krykewycz RG, Puchalsky MC, Rocks J, Bonnette B, Jaskiewicz F. Defining a primary market and estimating demand for major bicycle-sharing program in Philadelphia, Pennsylvania. Transportation Research Record: Journal of the Transportation Research Board. 2010; 2143: 117-124. Available from: doi:10.3141/2143-15

[2] Doolittle JT, Porter EK. Integration of bicycles and transit national academy press. Washington, DC; 1994.

[3] Martens K. The bicycle as a feedering mode: experiences from three European countries. Transportation Research part D: Transport and Environment. 2004;9(4): 281-294. Available from: doi:10.1016/j.trd.2004.02.005

[4] Martens K. Promoting bike-and-ride: the Dutch experience. Transportation Research part A: Policy and Practice. 2007;41(4): 326-338. Available from: doi:10.1016/ j.tra.2006.09.010

[5] Chen W, Chen KM. Study on connection of rail transit and bicycle traffic-a case study of Xi'an metro line2. Proceedings of the $3^{\text {rd }}$ International Conference on Civil Engineering for Architecture and Building Materials, Jinan, China; 2013.

[6] Kager R, Bertolini L, Brömmelstroet TM. Characterisation of and reflections on the synergy of bicycles and public transportation. Transportation Research Part A: Policy and Practice. 2016;85: 208-219. Available from: doi:10.1016/j.tra.2016.01.015

[7] Chen Q, Chen J. Evaluation on the transfer efficiency between intercity rail and conventional public transit. Proceedings of the $16^{\text {th }}$ COTA International Conference of Transportation, Shanghai, China; 2016.

[8] Song Y, Wang ZC, Wang MS, Huang SG. Evaluation of rail transit transfer efficiency. Proceedings of the $1^{\text {st }} \mathrm{In}$ ternational Conference on Railway Engineering: Highspeed Railway, Heavy Haul Railway and Urban Rail Transit, Beijing, China; 2010.

[9] Sun LS, Rong J, Ren F, Yao LY. Evaluation of passenger transfer efficiency of an urban public transportation terminal. Proceedings of the $10^{\text {th }}$ International IEEE Conference on Intelligent Transportation Systems, Bellevue, WA; 2007.

[10] Sun XN, Mai YY, Wang XG. The structural equation model for public evaluation of the transfer efficiency of rail transit P\&R facilities. Proceedings of the $3^{\text {rd }}$ International Conference on Green Building for Materials and 
Civil Engineering, Taiwan, China; 2013.

[11] Cheng HB, Huang ZD, Hu XJ. A MCDM/MADM model for evaluating efficiency of rail-bus transfer. Proceedings of the $5^{\text {th }}$ International Conference on Civil Engineering and Transportation, Guangzhou, China; 2016.

[12] Xu L, Zhang XC, Chen JH, Yu J. Transfer efficiency evaluation method of rail transit based on the generalized cost function. Proceedings of the $3^{\text {rd }}$ International Conference on Civil Engineering and Transportation, Guizhou, China; 2014.

[13] Guo Q, Wang YQ. Public bicycle and rail transit transfer efficiency evaluation-index system. Journal of Transportation Engineering and Information. 2014;12(1): 11-16.

[14] Xu Y, Yu S, Liu Y. Transfer efficiency evaluation between urban metro and buses with grey correlation method. Proceedings of the $5^{\text {th }}$ Advanced Forum on Transportation of China, Beijing, China; 2009.

[15] Zhu J, Zhao ZX, Qin Y, Wang ZY. Research on evaluation of transfer efficiency of rail transportation hub. Proceedings of the International Conference on System Science and Engineering, Dalian, China; 2012.

[16] Xia XM, Ma XD. Evaluation-index system of urban rail and bus transfer integration. Applied Mechanics and Materials. 2014;505-506: 809-812. Available from: doi:10.4028/www.scientific.net/amm.505-506.809

[17] Wang ZC, Wang LJ, Gao F. Evaluation of transfer efficiency for urban rail transit. Railway Transport and Economy. 2008;30(1): 74-76.

[18] Li PD. Evaluation study on station transfer coordination of rail transit and conventional transit in Harbin. $\mathrm{PhD}$ thesis. Chang' an University; 2015.

[19] Aghdaie MH, Hashemkhani ZS, Zavadskas EK. Market segment evaluation and selection based on application of fuzzy AHP and COPRAS-G methods. Journal of Business Economics and Management. 2013;14(1): 213-233. Available from: doi:10.3846/16111699.2012.721392

[20] Ertay T, Kahraman C, Kaya I. Evaluation of renewable energy alternatives using MACBETH and fuzzy AHP multicriteria methods: the case of Turkey. Technological and Economic Development of Economy. 2013;19(1): 38-62. Available from: doi:10.3846/20294913.2012.762 950

[21] Fouladgar MM, Yazdani-Chamzini A, Lashgari A, Zavadskas EK, Turskis Z. Maintenance strategy selection using AHP and COPRAS under fuzzy environment. International Journal of Strategic Property Management. 2012;16(1): 85-104. Available from: https://www.tandfonline.com/doi/abs/10.3846/1648715X.2012.666657

[22] Chen T, Jin YY, Qiu XP, Chen X. A hybrid fuzzy evaluation method for safety assessment of food-waste feed based on entropy and the analytic hierarchy process methods. Expert Systems with Application. 2014;41(16): 7328-7337. Available from: https://www.sciencedirect. com/science/article/pii/S095741741400342X

[23] Farhan J, Fwa TF. Pavement maintenance prioritization using analytic hierarchy process. Transportation Research Record: Journal of the Transportation Research Board. 2009;2093: 12-24.

[24] Stoilova S. An integrated approach for selection of intercity transport schemes on railway networks. Promet - Traffic \& Transportation. 2018;30(4): 367-377. Available from: doi:10.7307/ptt.v30i4.2673

[25] Saaty TL. The analytic hierarchy process. New York: McGraw-Hill; 1980.

[26] Su GH, Shi KB, Zhou F. Based on improvement AHP of construction project multi -objective optimal decision -making research. Water Conservancy Science and Technology and Economy. 2009;15(10): 867-870.

[27] Sun HY, Wang SF, Hao X. An improved analytic hierarchy process method for the evaluation of agricultural water management in irrigation districts of north China. Agricultural Water Management. 2017;179: 324-337. Available from: doi:10.1016/j.agwat.2016.08.002

[28] Shannon CE. A mathematical theory of communication. Bell System Technical Journal. 1948;27(3): 379-423.

[29] Wu G, Duan K, Zuo J, Zhao XB, Tang DZ. Integrated sustainability assessment of public rental housing community based on a hybrid method of AHP-entropy weight and cloud model. Sustainability. 2017; 9(4): 1-25. Available from: doi: 10.3390/su9040603.

[30] Huang WX, Cheng XW. Fuzzy evaluation of arable land suitability based on three scale AHP method. Proceedings of the International Conference on Geoinformatics, Wuhan, China, 2015.

[31] Niu L, Chen K, Cheng Y. Application of improved AHP in employment comprehensive evaluation. Computer Simulation. 2011;28(5): 376-379. 